\title{
Association of circulating neuregulin 4 with metabolic syndrome in obese adults: a cross-sectional study
}

\author{
Chengfu Cai ${ }^{1 \dagger}$, Mingzhu Lin ${ }^{2 \dagger}$, Yanfang $\mathrm{Xu}^{3}$, Xuejun Li ${ }^{2}$, Shuyu Yang ${ }^{2 *}$ and Huijie Zhang ${ }^{2,4^{*}}$
}

\begin{abstract}
Background: Neuregulin 4 (Nrg4) is a secreted adipokine recently identified as playing an important role in modulating systemic energy metabolism and the development of obesity-associated disorders. However, information is not available regarding the association between circulating Nrg4 and risk of metabolic syndrome (MetS) in humans.

Methods: We measured serum Nrg4 in 1212 obese adult subjects (aged 40 years or older), with a waist circumference greater than $90 \mathrm{~cm}$ for men or $80 \mathrm{~cm}$ for women, recruited from the community.

Results: MetS subjects had lower levels of circulating Nrg4 than healthy controls $(P<0.01)$. The prevalence of MetS was higher in subjects with lower levels of circulating Nrg4 compared to those with higher values (67.3\% vs. $57.4 \%, P<0.05$ ). Likewise, subjects with low levels of circulating Nrg4 had high prevalence of raised fasting glucose and blood pressure, but there was no association with raised triglycerides and reduced HDL-c. In multivariable logistic regression analyses, increased serum Nrg4 was significantly associated with reduced risk of MetS (OR: 0.603; $95 \% \mathrm{Cl}, 0.439-0.828 ; P=0.002$ ), adjusting for age, gender, current smoking, alcohol consumption, physical activity, $\mathrm{BMI}$, systolic blood pressure, fasting glucose, triglyceride, HDL-c, HOMA-IR, and body fat mass; however, such associations with serum Nrg4 were not noted for each component of MetS.

Conclusions: These findings indicate that circulating Nrg4 concentrations are inversely associated with risk of MetS in obese Chinese adults, suggesting that circulating Nrg4 concentrations may be a protective factor in the development of MetS.
\end{abstract}

Keywords: Neuregulin 4, Obesity, Metabolic syndrome, Body fat mass

\section{Background}

Metabolic syndrome (MetS) represents a cluster of multiple interrelated metabolic disorders, including obesity, insulin resistance, dyslipidaemia, hypertension, and hyperglycaemia [1,2]. MetS has gained importance because of its close association with type 2 diabetes and cardiovascular disease $[3,4]$. It has been well documented that excess adiposity is strongly associated with the development of MetS in the general population [5, 6]. Moreover, obesity-associated insulin resistance and low-

\footnotetext{
*Correspondence: xmyangshuyu@126.com; dr.hj_zhang@hotmail.com ${ }^{\dagger}$ Equal contributors

${ }^{2}$ Department of Endocrinology and Diabetes, The First Affiliated Hospital of Xiamen University, Teaching Hospital of Fujian Medical University, 55

Zhenhai Road, Xiamen 361003, China

Full list of author information is available at the end of the article
}

grade inflammation may largely account for the development of MetS [3, 7]. Previous research has indicated that several cytokines secreted by adipocytes, including resistin, leptin and adiponectin, have pro- and anti-inflammatory properties and are associated with incidence of type 2 diabetes, MetS, and cardiovascular disease [8-10].

Neuregulin $4(\mathrm{Nrg} 4)$ is a secreted adipokine recently identified as playing an important role in modulating systemic energy metabolism and in the development of metabolic disorders in rodent and human obesity, including type 2 diabetes and non-alcoholic fatty liver disease (NAFLD) [11]. As a brown fat-enriched endocrine factor, $\mathrm{Nrg} 4$ attenuates hepatic lipogenic signaling 
and preserves glucose and lipid homeostasis in obesity [12]. However, the relationship between circulating Nrg4 and metabolic disorder in human subjects remains largely unclear. To our knowledge, only one case-control study has tested circulating Nrg4 levels in 87 NAFLD subjects versus 87 non-NAFLD controls, and reported that circulating Nrg4 levels were decreased in NAFLD subjects [13]. Information is not available regarding the association between circulating Nrg4 and risk of MetS in humans. Accordingly, in the current study, we aimed to explore the association between circulating Nrg4 and risk of MetS in obese Chinese adults.

\section{Methods}

\section{Study participants}

Obese adults aged 40 years or older from the Lianqian community, Xiamen, China, were screened with physical examination from April 2011 to December 2013. The details of the study design and methods have been previously reported [14]. A total of 1212 adult obese subjects with a waist circumference greater than $90 \mathrm{~cm}$ for men or $80 \mathrm{~cm}$ for women were included in the analysis. Of them, 485 participants were randomly selected to further receive magnetic resonance spectroscopy for the measurement of hepatic fat content. All subjects completed a physical examination and a standard questionnaire including social-demographic status, lifestyle habits (i.e. smoking status, alcohol consumption and physical activity using the International Physical Activity Questionnaire), and medical history. Individuals were excluded if they had cancer, current treatment with systemic corticosteroids, biliary obstructive diseases, acute or chronic virus hepatitis, drug-induced liver diseases, total parenteral nutrition, autoimmune hepatitis, Wilson's disease, or known hyperor hypothyroidism.

All subjects provided written informed consent. The study protocol was approved by the Institutional Review Board of the First Affiliated Hospital of Xiamen University. The methods were carried out in accordance with the approved guidelines.

\section{Clinical and biochemical measurements}

Body weight was measured by using a spring scale, with participants wearing light clothing without shoes. Height was measured by using a vertical ruler. Body mass index (BMI, weight in kilograms divided by the square of the height in meters) was used as a measure of adiposity. Overweight (including obesity) was defined as BMI of 24 or higher, using the Working Group on Obesity in China criteria [15]. Waist circumference was measured at the level of the umbilicus. Three measurements were obtained with a non-stretchable tape, and the mean value was used for analysis. Blood pressure (BP) was assessed in triplicate using an electronic sphygmomanometer
(OMRON Company). The mean values of the three readings were used for analysis. Body fat mass was quantified using the HOLOGIC whole body DXA system (Hologic Inc., Bedford, MA). Intrahepatic triglyceride content was measured by magnetic resonance spectroscopy $\left({ }^{1} \mathrm{H}-\mathrm{MRS}\right.$; Avanto $3.0-\mathrm{T}$, Siemens AG, Erlangen, Germany) as described previously [16, 17]. Predicted resting energy expenditure was determined using the Harris-Benedict equation [18].

Subjects were instructed to fast for 12 hours before screening. A 75-g oral glucose tolerance tests and blood biochemical measurements were conducted for each subject. Triglycerides, total cholesterol and high-density lipoprotein cholesterol (HDL-c) were measured by enzymatic colorimetric methods with an automatic multichannel chemical analyzer (Hitachi 7450, Tokyo, Japan). Low-density lipoprotein cholesterol (LDL-c) was calculated using Friedewald's formula. Serum alanine aminotransferase and aspartate aminotransferase were measured by standard enzymatic methods. Serum gamma-glutamyltransferase was measured by the Szasz-Persijn method. Fasting plasma glucose concentrations and 2-h glucose concentrations were measured using the glucose oxidase method. Serum insulin concentrations were measured using an electrochemiluminescence immunoassay (Roche Elecsys Insulin Test, Roche Diagnostics, Mannheim, Germany). Insulin resistance status was assessed using the homeostasis model assessment of insulin resistance (HOMA) according to the following formula: fasting serum insulin $(\mu \mathrm{U} / \mathrm{mL}) \times$ fasting plasma glucose $(\mathrm{mmol} / \mathrm{L}) / 22.5$.

\section{Definition of metabolic syndrome (MetS)}

MetS was defined according to International Diabetes Federation diagnostic criteria [19], which included abdominal obesity (waist circumference $\geq 90 \mathrm{~cm}$ for Chinese men or $\geq 80 \mathrm{~cm}$ for Chinese women), plus two or more of the following: (1) reduced HDL-c $(<1.03 \mathrm{mmol} / \mathrm{L}$ for men or $<1.29 \mathrm{mmol} / \mathrm{L}$ for women, or specific treatment for this lipid abnormality), (2) raised triglyceride level $(\geq 1.7 \mathrm{mmol} / \mathrm{L}$, or specific treatment for this lipid abnormality), (3) raised BP ( $\geq 130 / 85 \mathrm{mmHg}$ or treatment of previously diagnosed hypertension), or (4) raised fasting plasma glucose $(\geq 5.6 \mathrm{mmol} / \mathrm{L}$ or previously diagnosed type 2 diabetes).

\section{Serum Nrg4 measurement}

Serum Nrg4 concentrations were measured using an enzyme-linked immunosorbent assay (ELISA) kits (Aviscera Biosciences, Santa Clara, CA). The assay has been shown to be highly sensitive to human Nrg4 with a sensitivity of $0.25 \mathrm{ng} / \mathrm{mL}$. The linear range of the standard was $0.5-32.0 \mathrm{ng} / \mathrm{mL}$, and the intra- and inter-assay variations were both less than $10 \%$. 


\section{Statistical analysis}

Data are presented as means \pm standard deviation (SD) or means \pm standard error (SEM) or median (interquartile range) for continuous variables or number and percentage for categorical variables. Serum Nrg4, triglycerides and HOMA-IR were log-transformed to improved normality before analytical comparisons. The subjects were classified into two groups according to metabolic status or four quartiles according to serum Nrg4 levels (Quartile 1: $<2.46 \mathrm{ng} / \mathrm{mL}$, Quartile 2: $2.47-3.34 \mathrm{ng} / \mathrm{mL}$, Quartile 3: $3.35-4.73 \mathrm{ng} / \mathrm{mL}$, and Quartile 4: $\geq 4.74 \mathrm{ng} / \mathrm{mL}$ ).

A $X^{2}$ test or logistic regression models were used to examine differences in categorical variables in different study groups. Analyses of covariance were performed using general linear models to test differences in study variables between different groups. In addition, we also performed sensitivity analyses stratified by gender or tertiles of serum Nrg4 levels. The correlation of serum Nrg4 levels with metabolic risk factors was analyzed by Pearson correlation coefficients. Multivariable logistic regression models were used to examine the association of serum Nrg4 levels with risks of MetS and components of MetS, adjusted for age, gender, smoking, alcohol consumption, physical activity, BMI, systolic BP, glucose, triglyceride, HDL-c, HOMA-IR, and body fat mass. Two-sided values of $P<0.05$ were considered statistically significant. All statistical analyses were performed with SAS version 9.3 (SAS Institute, Cary, NC).

\section{Results}

Table 1 summarizes the mean levels of study variables by subtypes of obese subjects. The mean age of the subjects was $53.3 \pm 7.3$ years. Within the sample, $41.2 \%$ (781/1212) of subjects had MetS. Compared with nonMetS subjects, MetS subjects had an unfavourable metabolic profile, including higher levels of BMI, fasting plasma glucose, postprandial glucose, systolic BP, diastolic BP, triglycerides, total cholesterol, body fat mass, and HOMA-IR, and lower levels of HDL-c. There was no difference in LDL-c between the two groups. Of interest, MetS subjects had lower serum Nrg4 levels than non-MetS subjects (3.24 (2.40-4.52) ng/mL vs. 3.55 (2.60-5.29) $\mathrm{ng} / \mathrm{mL}, P<0.01)$.

As shown in Fig. 1, serum Nrg4 levels were significantly reduced in subjects with raised fasting glucose (3.21 (2.38-4.58) vs. $3.53(2.60-5.05), P<0.001)$, raised BP (3.24 (2.37-4.59) vs. 3.49 (2.60-5.05), $P<0.05)$, or presence of MetS (3.24 (2.40-4.52) vs. 3.68 (2.62-5.53), $P<0.001)$ compared to their controls, adjusted for age, gender and BMI. However, there was no significant difference in serum Nrg4 levels according to overweight/ obesity (BMI $\geq 24$ ) and lipid profiles (including raised triglycerides and reduced HDL-c).

Table 2 presents the clinical characteristic by quartiles of serum Nrg4 levels, adjusted for age and gender. Gender and smoking status were significantly different between quartiles of serum Nrg4 levels. Diastolic BP,

Table 1 Clinical characteristics of obese subjects by metabolic syndrome

\begin{tabular}{|c|c|c|c|c|}
\hline Variables & Overall & Metabolic syndrome & Non-metabolic syndrome & $P$ value \\
\hline Sample size & 1212 & 781 & 431 & \\
\hline Age, years & $53.3 \pm 7.3$ & $54.3 \pm 7.2$ & $51.6 \pm 7.2$ & $<0.001$ \\
\hline Gender (male), n (\%) & $347(28.6)$ & $251(32.1)$ & $96(22.3)$ & $<0.001$ \\
\hline $\mathrm{BMl}, \mathrm{kg} / \mathrm{m}^{2}$ & $27.1 \pm 2.7$ & $27.4 \pm 2.8$ & $26.6 \pm 2.6$ & $<0.001$ \\
\hline Waist circumference, $\mathrm{cm}$ & $93.8 \pm 7.2$ & $94.7 \pm 7.4$ & $92.2 \pm 6.6$ & $<0.001$ \\
\hline Current smokers, n (\%) & $158(13.0)$ & $104(13.3)$ & $54(12.5)$ & 0.445 \\
\hline Systolic BP, mmHg & $133.3 \pm 17.5$ & $139.2 \pm 16.4$ & $122.6 \pm 14.2$ & $<0.001$ \\
\hline Diastolic BP, mmHg & $79.3 \pm 10.6$ & $82.3 \pm 10.3$ & $73.7 \pm 8.7$ & $<0.001$ \\
\hline Triglycerides, mmol/L & $1.6(1.1-2.3)$ & $1.9(1.4-2.7)$ & $1.5(1.1-2.0)$ & $<0.001$ \\
\hline Total cholesterol, mmol/L & $5.9 \pm 1.1$ & $6.0 \pm 1.1$ & $5.7 \pm 1.0$ & $<0.001$ \\
\hline LDL- cholesterol, mmol/L & $3.7 \pm 1.0$ & $3.7 \pm 1.0$ & $3.6 \pm 0.9$ & 0.533 \\
\hline HDL-cholesterol, mmol/L & $1.4 \pm 0.3$ & $1.3 \pm 0.3$ & $1.5 \pm 0.3$ & $<0.001$ \\
\hline Fasting glucose, $\mathrm{mmol} / \mathrm{L}$ & $6.1 \pm 1.7$ & $6.5 \pm 1.9$ & $5.5 \pm 0.9$ & $<0.001$ \\
\hline 2-h glucose, mmol/L & $9.0 \pm 4.0$ & $9.9 \pm 4.4$ & $7.2 \pm 2.3$ & $<0.001$ \\
\hline HOMA-IR & $2.92(2.10-4.25)$ & $2.81(2.04-4.04)$ & $2.83(1.84-3.99)$ & $<0.001$ \\
\hline Serum Nrg4, ng/mL & $3.35(2.47-4.74)$ & $3.24(2.40-4.52)$ & $3.55(2.60-5.29)$ & 0.002 \\
\hline Body fat mass, kg & $24.0 \pm 5.3$ & $24.3 \pm 5.4$ & $23.5 \pm 5.1$ & 0.013 \\
\hline
\end{tabular}

Data are presented as the mean \pm SD or median (interquartile range)

$B M I$ body mass index, HOMA-IR homeostasis model assessment of insulin resistance, Nrg4 Neuregulin 4 


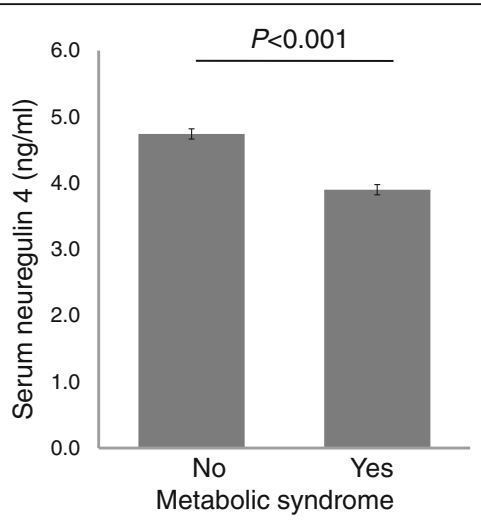

A

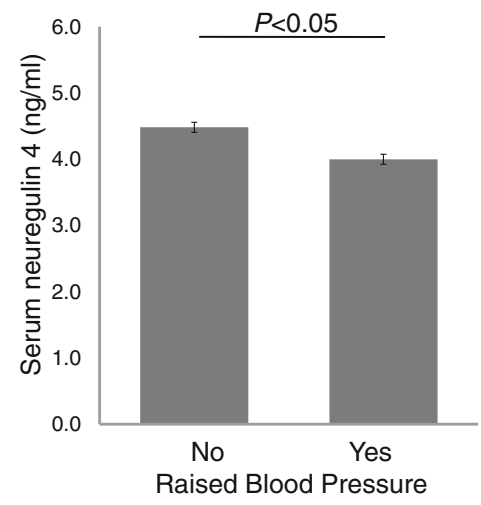

C

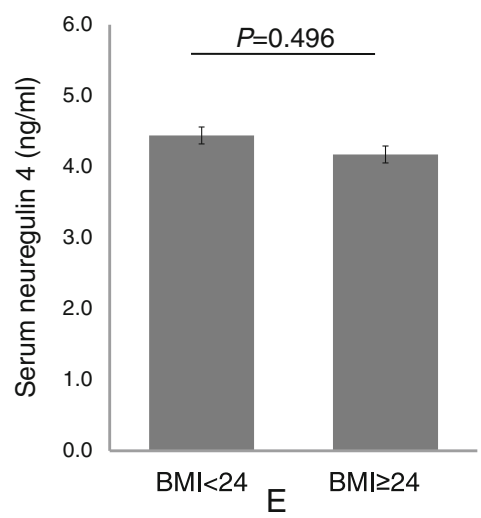

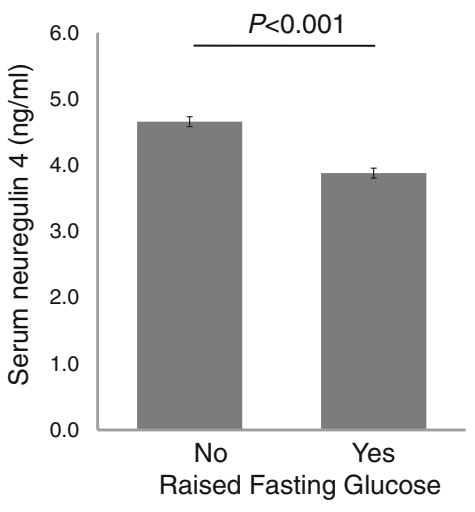

B

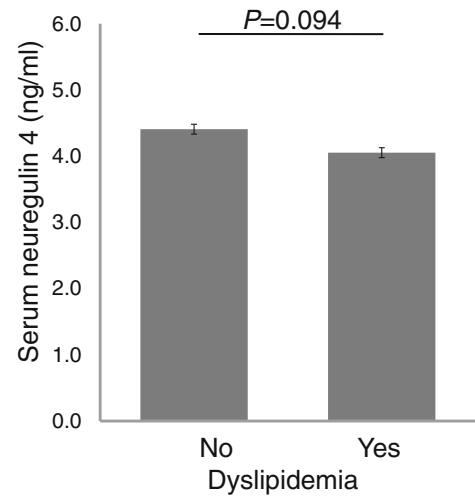

D

Fig. 1 Serum neuregulin 4 (Nrg4) levels according to components of metabolic syndrome (MetS). a Serum Nrg4 levels by presence of MetS. b Serum Nrg4 levels by presence of raised fasting glucose. c Serum Nrg4 levels by presence of raised blood pressure. $\mathbf{d}$ Serum Nrg4 levels by presence of raised triglycerides or reduced HDL-cholesterol. e Serum Nrg4 levels by presence of overweight/obesity; ${ }^{*} P<0.05 ;{ }^{* *} P<0.01 ; B M I$, body mass index

total cholesterol, triglyceride, LDL-c, HDL-c, postprandial glucose, and HOMA-IR showed no significant differences among the four quartiles of serum Nrg4 levels, adjusted for age and gender. In addition, resting energy expenditure showed no significant difference among the four groups, adjusted for age and gender. Compared to subjects in the lowest quartile of serum Nrg4 levels, those in the highest quartile had significantly lower levels of BMI, waist circumference, and body fat mass $(P<0.05)$. Fasting glucose was reduced gradually with the increase of serum Nrg4 $(P<0.01)$. Of note, the prevalence of MetS was significantly higher in subjects with lower levels of serum Nrg4 than those with higher values $(67.3 \%$ vs. $57.4 \%, P<0.05)$. With respect to 
Table 2 Clinical characteristics by quartiles of serum neuregulin 4 (Nrg4) levels in obese subjects

\begin{tabular}{|c|c|c|c|c|c|}
\hline \multirow[t]{2}{*}{ Variables } & \multicolumn{4}{|l|}{ Serum Nrg4 level } & \multirow{2}{*}{$\begin{array}{l}P \text { value for } \\
\text { trend* }\end{array}$} \\
\hline & Quartile 1 & Quartile 2 & Quartile 3 & Quartile 4 & \\
\hline Sample size & 303 & 302 & 304 & 303 & \\
\hline Serum Nrg4, ng/mL & $1.95(1.56-2.23)$ & $2.88(2.70-3.10)$ & $3.90(3.59-4.31)$ & $6.62(5.41-9.13)$ & $<0.001$ \\
\hline Age, years & $52.2 \pm 7.7$ & $53.4 \pm 7.1$ & $53.4 \pm 7.1$ & $54.4 \pm 7.1$ & 0.570 \\
\hline Gender (male), n (\%) & $126(41.6)$ & $84(27.8)$ & $77(25.3)$ & $61(20.1)$ & $<0.001$ \\
\hline $\mathrm{BMl}, \mathrm{kg} / \mathrm{m}^{2}$ & $27.5 \pm 2.8$ & $27.05 \pm 2.7$ & $27.2 \pm 2.6$ & $26.7 \pm 2.7^{* *}$ & 0.104 \\
\hline Resting energy expenditure, kcal/day & $1476.6 \pm 189.3$ & $1415.4 \pm 191.8^{* * *}$ & $1414.1 \pm 165.3^{* * *}$ & $1384.3 \pm 156.0^{* * *}$ & 0.491 \\
\hline Waist circumference, cm & $95.2 \pm 7.3$ & $93.4 \pm 7.5$ & $93.9 \pm 6.9$ & $92.8 \pm 7.1^{* *}$ & 0.068 \\
\hline Current smokers, n (\%) & $57(18.8)$ & $37(12.3)$ & $35(11.5)$ & $29(9.6)$ & 0.005 \\
\hline Systolic BP, mmHg & $134.1 \pm 17.6$ & $133.0 \pm 17.5$ & $134.3 \pm 18.3$ & $131.9 \pm 16.8$ & 0.286 \\
\hline Diastolic BP, mmHg & $79.8 \pm 10.3$ & $79.3 \pm 10.9$ & $79.6 \pm 10.8$ & $78.3 \pm 10.5$ & 0.658 \\
\hline Triglycerides, mmol/L & $1.6(1.1-2.3)$ & $1.6(1.0-2.4)$ & $2.3(1.1-2.3)$ & $1.5(1.0-2.2)$ & 0.522 \\
\hline Total cholesterol, mmol/L & $5.9 \pm 1.1$ & $5.9 \pm 1.1$ & $5.9 \pm 1.0$ & $5.8 \pm 1.1$ & 0.396 \\
\hline LDL-cholesterol, mmol/L & $3.7 \pm 1.0$ & $3.7 \pm 1.0$ & $3.7 \pm 0.9$ & $3.6 \pm 1.0$ & 0.353 \\
\hline HDL-cholesterol, mmol/L & $1.4 \pm 0.3$ & $1.4 \pm 0.3$ & $1.4 \pm 0.3$ & $1.4 \pm 0.3$ & 0.302 \\
\hline Fasting glucose, mmol/L & $6.3 \pm 2.0$ & $6.2 \pm 1.9$ & $6.1 \pm 1.6$ & $5.9 \pm 1.2^{* * *}$ & 0.009 \\
\hline 2-h glucose, $\mathrm{mmol} / \mathrm{L}$ & $9.1 \pm 4.3$ & $9.0 \pm 4.1$ & $9.0 \pm 4.0$ & $8.7 \pm 3.6$ & 0.255 \\
\hline HOMA-IR & $2.99(2.09-4.38)$ & $3.08(2.07-4.26)$ & $2.99(2.17-4.29)$ & $2.74(2.05-3.99)$ & 0.229 \\
\hline Body fat mass, kg & $24.1 \pm 5.4$ & $23.9 \pm 5.6$ & $24.4 \pm 5.3$ & $23.8 \pm 5.1^{* *}$ & 0.047 \\
\hline Metabolic syndrome, n (\%) & $204(67.3)$ & $205(67.9)$ & $198(65.1)$ & $174(57.4)^{* *}$ & 0.006 \\
\hline \multicolumn{6}{|l|}{ Components of metabolic syndrome } \\
\hline Raised blood pressure, n (\%) & $190(62.7)$ & $181(59.7)$ & $175(57.6)$ & $162(53.3)^{* *}$ & 0.021 \\
\hline Raised fasting glucose, n (\%) & $191(63.0)$ & $188(61.8)$ & $174(57.2)^{* *}$ & $164(54.0)^{* * *}$ & $<0.001$ \\
\hline Raised triglycerides, n (\%) & $141(46.5)$ & $143(47.2)$ & $144(47.4)$ & $121(39.9)$ & 0.446 \\
\hline Reduced HDL-cholesterol, n (\%) & $76(25.1)$ & $113(37.3)^{* * *}$ & $95(31.3)$ & $98(32.3)$ & 0.521 \\
\hline
\end{tabular}

Data are presented as the mean \pm SD or median (interquartile range)

*Adjusted for age and gender

${ }^{*} P<0.05$ compared with Q1 of serum Nrg4

***P $<0.01$ compared with Q1 of serum Nrg4

Nrg4 Neuregulin 4, BMI body mass index, BP blood pressure, HOMA-IR homeostasis model assessment of insulin resistance

individual components of MetS, prevalence of raised fasting glucose and blood pressure was significantly higher in participants with lower levels of serum Nrg4 than those with higher values; however, prevalence of raised triglycerides and reduced HDL-cholesterol showed no significant difference across quartiles of serum Nrg4 levels.

Clinical characteristic by gender and tertiles of serum $\mathrm{Nrg} 4$ levels was substantially similar to those shown in Table 2 (Additional file 1: Table S1). Male subjects had lower levels of serum Nrg4 than female subjects, adjusted for age, current smoking, alcohol consumption and physical activity $(3.00(2.12-4.01) \mathrm{ng} / \mathrm{mL}$ vs. 3.52 $(2.62-5.07) \mathrm{ng} / \mathrm{mL}, P<0.01)$. Compared to female subjects in the first tertile of serum Nrg4 levels, those in the third tertile had significantly lower levels of systolic BP, waist circumference, fasting glucose and postprandial glucose $(P<0.05)$. Both male and female subjects with lower levels of serum Nrg4 had higher prevalence of MetS than those with higher values (both $P<0.05$ ). Additionally, there was no significant difference in serum Nrg4 levels according to smoking status (Additional file 1: Table S2).

Intrahepatic triglyceride content and liver enzymes were assessed by quartiles of serum Nrg4 levels in 485 obese adults (Additional file 2: Figure S1). Intrahepatic triglyceride content was reduced gradually with the increase in serum Nrg4 levels $(15.5 \pm 10.8 \%$ in quartile 1 , $14.9 \pm 10.7 \%$ in quartile $2,12.9 \pm 9.2 \%$ in quartile 3 , $12.0 \pm 9.0 \%$ in quartile $4, P<0.05$ for trend). Serum alanine aminotransferase, aspartate aminotransferase and gamma-glutamyltransferase showed no significant differences among the four quartiles of serum Nrg4 levels (all $P>0.05$ ). 
As shown in Table 3, serum Nrg4 levels were significantly correlated with BMI, waist circumference, LDL-c, fasting glucose and body fat mass, adjusting for age, gender, smoking, alcohol consumption and physical activity.

The multivariable-adjusted odds ratios (ORs) for the association between serum Nrg4 levels and components of MetS are shown in Table 4. After adjustment for age, gender, current smoking, alcohol consumption and physical activity, increased serum Nrg4 was significantly associated with reduced risk of raised fasting glucose and prevalence of MetS (OR: 0.809; 95 \% CI, 0.657-0.997 and 0.769; 0.621-0.952, respectively); however, serum Nrg4 was not significantly associated with risks of raised blood pressure $(P=0.057)$, raised triglycerides $(P=0.899)$ or reduced HDL-cholesterol $(P=0.991)$. Furthermore, increased serum Nrg4 was significantly associated with reduced risk of MetS (OR: 0.615; 95 \% CI, 0.450-0.841; $P=0.002$ ), even after adjusting for age, gender, current smoking, alcohol consumption, physical activity, BMI, systolic BP, fasting glucose, triglycerides and HDL-c; however, such associations of serum Nrg4 were not noted for each component of MetS. After further adjustment for HOMA-IR and body fat mass, the relationship between serum Nrg4 and MetS remained significant (OR: 0.603; $95 \%$ CI, 0.439-0.828; $P=0.002$ ).

\section{Discussion}

Nrg4 is a brown fat-enriched endocrine factor recently been shown to improve obesity-associated disorders, including type 2 diabetes and NAFLD [12, 20]. In the present study, we provide, for the first time, evidence

Table 3 Clinical correlates of serum neuregulin 4 (Nrg4) levels with metabolic risk factors

\begin{tabular}{|c|c|c|c|}
\hline & $\begin{array}{l}\text { Correlation } \\
\text { coefficient }\end{array}$ & $P$ value & $\begin{array}{l}\text { Multiple adjusted } \\
P \text { value* }^{*}\end{array}$ \\
\hline Age, years & 0.105 & $<0.001$ & - \\
\hline Gender $($ male $=1$, female $=2)$ & - & $<0.001$ & - \\
\hline $\mathrm{BMI}, \mathrm{kg} / \mathrm{m}^{2}$ & -0.099 & $<0.001$ & 0.011 \\
\hline Waist circumference, cm & -0.112 & $<0.001$ & 0.034 \\
\hline Systolic BP, mmHg & -0.038 & 0.190 & 0.381 \\
\hline Diastolic BP, mmHg & -0.047 & 0.105 & 0.944 \\
\hline Total cholesterol, mmol/L & -0.019 & 0.512 & 0.079 \\
\hline Total triglycerides, mmol/L & -0.053 & 0.067 & 0.617 \\
\hline LDL-cholesterol, mmol/L & -0.015 & 0.602 & 0.025 \\
\hline HDL-cholesterol, mmol/L & 0.049 & 0.091 & 0.464 \\
\hline Fasting glucose, mmol/L & -0.098 & $<0.001$ & 0.007 \\
\hline HOMA-IR & -0.047 & 0.104 & 0.266 \\
\hline Body fat mass, kg & -0.0005 & 0.988 & 0.013 \\
\hline
\end{tabular}

$B M I$ body mass index, BP blood pressure, HOMA-IR homeostasis model assessment of insulin resistance

*Adjusted for age, gender, smoking, alcohol consumption, and physical activity
Table 4 Odds ratios of components of metabolic syndrome according to serum neuregulin 4 (Nrg4)

\begin{tabular}{llll}
\hline Components of metabolic syndrome & OR & $95 \% \mathrm{Cl}$ & $P$ value \\
\hline Model 1 & & & \\
Raised blood pressure & 0.814 & $0.658-1.006$ & 0.057 \\
Raised fasting glucose & 0.809 & $0.657-0.997$ & 0.047 \\
Raised triglycerides & 0.987 & $0.806-1.208$ & 0.899 \\
Reduced HDL-cholesterol & 0.999 & $0.803-1.243$ & 0.991 \\
Metabolic syndrome & 0.769 & $0.621-0.952$ & 0.016 \\
Model 2 & & & \\
Raised blood pressure & 0.824 & $0.662-1.026$ & 0.084 \\
Raised fasting glucose & 0.838 & $0.674-1.042$ & 0.112 \\
Raised triglycerides & 1.034 & $0.838-1.277$ & 0.754 \\
Reduced HDL-cholesterol & 1.047 & $0.836-1.312$ & 0.689 \\
Metabolic syndrome & 0.615 & $0.450-0.841$ & 0.002 \\
Model 3 & & & \\
Raised blood pressure & 0.822 & $0.660-1.024$ & 0.080 \\
Raised fasting glucose & 0.806 & $0.635-1.022$ & 0.075 \\
Raised triglycerides & 1.023 & $0.827-1.266$ & 0.834 \\
Reduced HDL-cholesterol & 1.048 & $0.837-1.314$ & 0.681 \\
Metabolic syndrome & 0.603 & $0.439-0.828$ & 0.002 \\
\hline OR & & &
\end{tabular}

$O R$ odds ratio, $\mathrm{Cl}$ confidence interval, $B M I$ body mass index, HOMA-IR homeostasis model assessment of insulin resistance

Model 1: adjusted for age, gender, smoking, alcohol consumption and physical activity

Model 2: adjusted for model $1+\mathrm{BMI}$, SBP, glucose, total cholesterol, triglyceride and $\mathrm{HDL}-\mathrm{C}$

Model 3: adjusted for model $2+$ HOMA-IR and body fat mass

that circulating Nrg4 concentrations are significantly reduced in subjects with MetS as well as those with particular components. Furthermore, lower circulating Nrg4 concentrations were independently associated with increased risk of MetS in obese Chinese adults. These findings indicate that circulating Nrg4 could be a protective factor in the pathogenesis of MetS.

Brown adipose tissue activates uncoupled respiration in response to cold temperature and contributes to systemic metabolic homeostasis [21-23]. It has been established that brown adipose tissue is metabolically active in adult humans and correlated with body composition and energy metabolism [24-26]. Activation of brown adipose tissue increases energy expenditure and leads to reduced adiposity, which has provided new insight into the prevention of obesity and MetS [11, 27, 28]. Wang et al. [12] reported that the brown fat-enriched secreted factor Nrg4 attenuated hepatic lipogenic signaling and preserved glucose and lipid homeostasis in obesity. Unfortunately, information regarding the association of circulating Nrg4 with hepatic fat content and energy expenditure in humans is limited. Our data demonstrated that circulating Nrg4 was not significantly associated with 
predicted resting energy expenditure, suggesting that Nrg4 may not directly engage in brown fat thermogenesis [12]. A case-control study also reported that circulating Nrg4 was significantly decreased in 87 NAFLD subjects versus 87 non-NAFLD controls [13]. In the present study, we provided new clinical evidence revealing that serum $\mathrm{Nrg} 4$ levels were inversely associated with hepatic fat content in obese adults (Additional file 2: Figure S1). These data suggest that $\mathrm{Nrg} 4$ appears to be involved in crosstalk between brown fat tissue and obesity-associated disorders, including NAFLD and MetS. However, the potential roles of circulating Nrg4 in contributing to obesity-associated disorders and the associations of circulating Nrg4 with metabolic risk factors and MetS remain to be elucidated in population-based studies.

Previous studies have indicated that adipose tissue Nrg4 expression was reduced in obesity and negatively correlated with body fat mass in humans [12, 29], but the association of circulating Nrg4 with body fat mass has been not yet studied. Our findings indicate that circulating $\mathrm{Nrg} 4$ is negatively correlated with body fat mass in obese adults. In contrast, Dai et al. [13] reported that circulating Nrg4 was not significantly associated with BMI in a case-control study of 87 NAFLD subjects versus 87 non-NAFLD controls. In the present study, with a sample size of more than 1000 obese adults, we found that circulating Nrg4 was negatively associated with waist circumference and BMI. Therefore, these data indicate that Nrg4 insufficiency may be a common feature of obesity in the general population.

Excess adiposity is associated with MetS as well as metabolic risk factors, i.e. hyperglycaemia, elevated BP and dyslipidaemia [8, 30, 31]. Nrg4 has been identified as being involved in crosstalk between brown fat tissue and obesity-associated disorders [32]. However, limited evidence is available regarding whether circulating Nrg4 is involved in the development of MetS in adults. Dai et al. [13] did not find a significant association of circulating Nrg4 with fasting glucose in 174 NAFLD and nonNAFLD subjects. Kang et al. [33] reported that circulating Nrg4 levels were significantly higher in 57 patients with diabetes mellitus compared with 59 controls without diabetes and were correlated with the serum glucose level and insulin resistance. It should be noted that limited evidence is based on case-control study designs, and sample sizes of all of the studies above are quite small (less than 200 subjects). In contrast, our data demonstrate that circulating $\mathrm{Nrg} 4$ is significantly decreased in individuals with hyperglycaemia compared to their controls and inversely associated with fasting glucose in more than 1000 obese adults. These findings suggest that low circulating Nrg4 is associated with increased risk of diabetes. Prospective cohort studies are needed to confirm this finding and elucidate the potential underlying mechanisms. In addition, our data indicates that circulating Nrg4 is significantly decreased in individuals with elevated blood pressure, whereas there is no significant difference in circulating Nrg4 levels in individuals with raised triglycerides or reduced HDL-c compared to controls.

Interestingly, our data demonstrates that circulating Nrg4 was significantly decreased in individuals with MetS compared to controls and independently associated with risk of MetS. To date, this is the first population-based study to evaluate the association of circulating Nrg4 and MetS. The findings indicate that each SD increase in circulating Nrg4 levels (log-transformed) is associated with a $38.5 \%$ decrease in the risk of MetS. $\mathrm{Nrg} 4$ is expressed in adipocytes, the deficiency of which exacerbates diet-induced insulin resistance and obesity in animal models [12, 29]. However, adjustment for insulin resistance and body fat mass did not attenuate the association of circulating Nrg4 with risk of MetS in the current study. These findings indicate that low circulating Nrg4 appears to add to the risk of MetS independently of obesity and insulin resistance. Indeed, our findings show that circulating Nrg4 is significantly associated with fatty liver, which may play a role in the development of MetS [34]. However, the effect of Nrg4 in the development of MetS needs to be further studied in vivo and in vitro. As a novel endocrine factor, circulating Nrg4 may activate the receptor kinases ErbB3 and ErbB4 and coordinate glucose and lipid homeostasis in obesity $[12,35]$. Therefore, Nrg4 may play a potential role in therapeutic developments for MetS.

This community-based, cross-sectional study provided an opportunity to determine the role of circulating Nrg4 in predicting the development of MetS. Nevertheless, there are several limitations to the current study. First, the study was based on cross-sectional data with a relatively limited sample size, and the population consisted of only obese adults. Therefore, further studies are warranted to determine the role of circulating $\mathrm{Nrg} 4$ in the development of MetS in the general population. Second, given its cross-sectional design, it is not possible to determine a causal relationship between circulating Nrg4 and the development of MetS. Therefore, the causal association between circulating $\mathrm{Nrg} 4$ and MetS should be further evaluated in prospective cohort studies with larger sample sizes and long follow-up periods.

\section{Conclusions}

Our study provides, for the first time, clinical evidence revealing that circulating Nrg4 concentrations are inversely associated with risk of MetS in obese Chinese adults. These findings suggests that circulating Nrg4 concentrations may be a protective factor in the development of MetS and underscore the importance of Nrg4 as a potential therapeutic target for MetS. 


\section{Additional files}

Additional file 1: Table S1. Clinical characteristics by gender and tertiles of serum neuregulin 4 (Nrg4) levels. Table S2. Serum Nrg4 levels according to smoking status. (DOCX $27 \mathrm{~kb}$ )

Additional file 2: Figure S1. Intrahepatic triglyceride content and liver enzymes by quartiles of serum neuregulin 4 (Nrg4) levels in 485 obese adults. (PPTX $70 \mathrm{~kb}$ )

\section{Acknowledgments}

This study was supported by grants from the China Natural Science Foundation (81570785), Young Talent Foundation of Fujian Provincial Health Department (2013-ZQN-ZD-31), and the Xiamen Systems Biology Research Program for Metabolic Disease (3502Z20100001). Dr. Huijie Zhang was partially supported by a research training grant (D43TW009107) from the John E Fogarty International Center of the National Institutes of Health, Bethesda, MD. We also acknowledge the editorial assistance of Miss Katherine Obst.

\section{Authors' contributions}

$\mathrm{CC}, \mathrm{ML}$, SY and $\mathrm{HZ}$ generated the hypothesis, directed the implementation, and wrote the manuscript. YX and CC contributed to analytic strategy and statistical analyses. $\mathrm{HZ}, \mathrm{SY}, \mathrm{XL}$ and $\mathrm{ML}$ supervised the field activities and data collection and edited the manuscript. All authors read and approved the final manuscript.

\section{Competing interests}

The authors declare that they have no competing interests.

\section{Author details}

${ }^{1}$ Department of Otolaryngology Head and Neck Surgery, The First Affiliated Hospital of Xiamen University, Teaching Hospital of Fujian Medical University, Xiamen, China. ${ }^{2}$ Department of Endocrinology and Diabetes, The First Affiliated Hospital of Xiamen University, Teaching Hospital of Fujian Medical University, 55 Zhenhai Road, Xiamen 361003, China. ${ }^{3}$ Department of Nephrology, The First Affiliated Hospital, Fujian Medical University, Fuzhou, China. ${ }^{4}$ Department of Epidemiology, Tulane University Health Sciences Center, New Orleans, LA, USA.

Received: 4 July 2016 Accepted: 21 September 2016

\section{Published online: 24 October 2016}

\section{Reference}

1. Malik S, Wong ND, Franklin SS, Kamath TV, L'Italien GJ, Pio JR, Williams GR. Impact of the metabolic syndrome on mortality from coronary heart disease, cardiovascular disease, and all causes in United States adults. Circulation. 2004;110(10):1245-50.

2. Liu L, Miura K, Fujiyoshi A, Kadota A, Miyagawa N, Nakamura Y, Ohkubo T, Okayama A, Okamura T, Ueshima H. Impact of metabolic syndrome on the risk of cardiovascular disease mortality in the United States and in Japan. Am J Cardiol. 2014;113(1):84-9.

3. Jensen MD, Ryan DH, Apovian CM, Ard JD, Comuzzie AG, Donato KA, Hu FB, Hubbard VS, Jakicic JM, Kushner RF, et al. 2013 AHA/ACC/TOS guideline for the management of overweight and obesity in adults: a report of the American College of Cardiology/American Heart Association Task Force on Practice Guidelines and The Obesity Society. J Am Coll Cardiol. 2014:63(25 Pt B):2985-3023.

4. Aguilar M, Bhuket T, Torres S, Liu B, Wong RJ. Prevalence of the metabolic syndrome in the United States, 2003-2012. JAMA. 2015:313(19):1973-4.

5. Andrus B, Lacaille D. 2013 ACC/AHA guideline on the assessment of cardiovascular risk. J Am Coll Cardiol. 2014;63(25 Pt A):2886.

6. Cornier MA, Dabelea D, Hernandez TL, Lindstrom RC, Steig AJ, Stob NR, Van Pelt RE, Wang H, Eckel RH. The metabolic syndrome. Endocr Rev. 2008:29(7):777-822.

7. Dandona P, Aljada A, Chaudhuri A, Mohanty P, Garg R. Metabolic syndrome: a comprehensive perspective based on interactions between obesity, diabetes, and inflammation. Circulation. 2005;111(11):1448-54.

8. Berg $\mathrm{AH}$, Scherer PE. Adipose tissue, inflammation, and cardiovascular disease. Circ Res. 2005;96(9):939-49.
9. Reilly MP, Lehrke M, Wolfe ML, Rohatgi A, Lazar MA, Rader DJ. Resistin is an inflammatory marker of atherosclerosis in humans. Circulation. 2005;111(7):932-9.

10. Sook Lee E, Park SS, Kim E, Sook Yoon Y, Ahn HY, Park CY, Ho Yun Y, Woo Oh S. Association between adiponectin levels and coronary heart disease and mortality: a systematic review and meta-analysis. Int J Epidemiol. 2013;42(4):1029-39.

11. Wang GX, Zhao XY, Lin JD. The brown fat secretome: metabolic functions beyond thermogenesis. Trends Endocrinol Metab. 2015;26(5):231-7.

12. Wang GX, Zhao XY, Meng ZX, Kern M, Dietrich A, Chen Z, Cozacov Z, Zhou D, Okunade AL, Su X, et al. The brown fat-enriched secreted factor Nrg4 preserves metabolic homeostasis through attenuation of hepatic lipogenesis. Nat Med. 2014;20(12):1436-43.

13. Dai YN, Zhu JZ, Fang ZY, Zhao DJ, Wan XY, Zhu HT, Yu CH, Li YM. A case-control study: association between serum neuregulin 4 level and non-alcoholic fatty liver disease. Metabolism. 2015;64(12):1667-73.

14. Pan LL, Zhang HJ, Huang ZF, Sun Q, Chen Z, Li ZB, Yang SY, Li XY, Li XJ. Intrahepatic triglyceride content is independently associated with chronic kidney disease in obese adults: a cross-sectional study. Metabolism. 2015;64(9):1077-85.

15. Zhou BF, Cooperative Meta-Analysis Group of the Working Group on Obesity in China. Predictive values of body mass index and waist circumference for risk factors of certain related diseases in Chinese adults-study on optimal cut-off points of body mass index and waist circumference in Chinese adults. Biomed Environ Sci. 2002;15(1):83-96.

16. Zhang HJ, Zhang XF, Ma ZM, Pan LL, Chen Z, Han HW, Han CK, Zhuang XJ, Lu Y, Li XJ, et al. Irisin is inversely associated with intrahepatic triglyceride contents in obese adults. J Hepatol. 2013:59(3):557-62.

17. Frimel TN, Deivanayagam S, Bashir A, O'Connor R, Klein S. Assessment of intrahepatic triglyceride content using magnetic resonance spectroscopy. J Cardiometab Syndr. 2007;2(2):136-8

18. Japur CC, Penaforte FR, Chiarello PG, Monteiro JP, Vieira MN, Basile-Filho A Harris-Benedict equation for critically ill patients: are there differences with indirect calorimetry? J Crit Care. 2009;24(4):628. e1-5.

19. Alberti KG, Zimmet $P$, Shaw J. The metabolic syndrome-a new worldwide definition. Lancet. 2005;366(9491):1059-62.

20. Rosell M, Kaforou M, Frontini A, Okolo A, Chan YW, Nikolopoulou E, Millership S, Fenech ME, Maclntyre D, Turner JO, et al. Brown and white adipose tissues: intrinsic differences in gene expression and response to cold exposure in mice. Am J Physiol Endocrinol Metab. 2014;306(8):E945-64

21. Yoneshiro T, Aita S, Matsushita M, Kayahara T, Kameya T, Kawai Y, Iwanaga T, Saito M. Recruited brown adipose tissue as an antiobesity agent in humans. J Clin Invest. 2013;123(8):3404-8.

22. Cannon B, Nedergaard J. Brown adipose tissue: function and physiological significance. Physiol Rev. 2004;84(1):277-359.

23. Kozak LP, Harper ME. Mitochondrial uncoupling proteins in energy expenditure. Annu Rev Nutr. 2000:20:339-63.

24. Bakker $L E$, Boon MR, van der Linden RA, Arias-Bouda LP, van Klinken JB, Smit F, Verberne HJ, Jukema JW, Tamsma JT, Havekes LM, et al. Brown adipose tissue volume in healthy lean south Asian adults compared with white Caucasians: a prospective, case-controlled observational study. Lancet Diabetes Endocrinol. 2014:2(3):210-7.

25. Cypess AM, Lehman S, Williams G, Tal I, Rodman D, Goldfine AB, Kuo FC, Palmer EL, Tseng YH, Doria A, et al. Identification and importance of brown adipose tissue in adult humans. N Engl J Med. 2009:360(15):1509-17.

26. van Marken Lichtenbelt WD, Vanhommerig JW, Smulders NM, Drossaerts JM, Kemerink GJ, Bouvy ND, Schrauwen P, Teule GJ. Cold-activated brown adipose tissue in healthy men. N Engl J Med. 2009;360(15):1500-8.

27. Chondronikola M, Volpi E, Borsheim E, Porter C, Saraf MK, Annamalai P, Yfanti C, Chao T, Wong D, Shinoda K, et al. Brown adipose tissue activation is linked to distinct systemic effects on lipid metabolism in humans. Cell Metab. 2016:23(6):1200-6.

28. Hoeke G, Kooijman S, Boon MR, Rensen PC, Berbee JF. Role of brown fat in lipoprotein metabolism and atherosclerosis. Circ Res. 2016:118(1):173-82.

29. Ma Y, Gao M, Liu D. Preventing high fat diet-induced obesity and improving insulin sensitivity through neuregulin 4 gene transfer. Sci Rep. 2016;6:26242

30. Fox CS, Massaro JM, Hoffmann U, Pou KM, Maurovich-Horvat P, Liu CY, Vasan RS, Murabito JM, Meigs JB, Cupples LA, et al. Abdominal visceral and subcutaneous adipose tissue compartments: association with metabolic risk factors in the Framingham Heart Study. Circulation. 2007;116(1):39-48. 
31. Shulman Gl. Ectopic fat in insulin resistance, dyslipidemia, and cardiometabolic disease. N Engl J Med. 2014;371(12):1131-41.

32. Pfeifer A. NRG4: an endocrine link between brown adipose tissue and liver. Cell Metab. 2015;21(1):13-4.

33. Kang YE, Kim JM, Choung S, Joung KH, Lee JH, Kim HJ, Ku BJ. Comparison of serum Neuregulin 4 (Nrg4) levels in adults with newly diagnosed type 2 diabetes mellitus and controls without diabetes. Diabetes Res Clin Pract. 2016;117:1-3.

34. Kotronen A, Yki-Jarvinen $\mathrm{H}$. Fatty liver: a novel component of the metabolic syndrome. Arterioscler Thromb Vasc Biol. 2008;28(1):27-38.

35. Bernard JK, McCann SP, Bhardwaj V, Washington MK, Frey MR. Neuregulin-4 is a survival factor for colon epithelial cells both in culture and in vivo. J Biol Chem. 2012;287(47):39850-8.

Submit your next manuscript to BioMed Central and we will help you at every step:

- We accept pre-submission inquiries

- Our selector tool helps you to find the most relevant journal

- We provide round the clock customer support

- Convenient online submission

- Thorough peer review

- Inclusion in PubMed and all major indexing services

- Maximum visibility for your research

Submit your manuscript at www.biomedcentral.com/submit
Biomed Central 